\title{
Clinical relevance of testing for antineutrophil cytoplasm antibodies (ANCA) with a standard indirect immunofluorescence ANCA test in patients with upper or lower respiratory tract
} symptoms

\author{
A Davenport, R J Lock, T B Wallington
}

\begin{abstract}
Background - Reports from specialist nephrological centres have suggested that the antineutrophil cytoplasm antibody (ANCA) test is highly specific and sensitive for patients with Wegener's granulomatosis. To determine the usefulness of the ANCA test in everyday respiratory practice the results of the test were audited in all patients in the south west of England with respiratory symptoms who underwent the test.
\end{abstract}

Methods - The results of all 335 patients who had presented with upper or lower respiratory tract symptoms, or both, and were tested for ANCA by the indirect ANCA test in 1990, as recommended in the broadsheet of the British Association of Clinical Pathologists, were audited. Case notes and necropsy reports were available for review in 231 cases $(69 \%)$, and in the remainder information was obtained by a standard questionnaire.

Results - There were 106 positive results, $45(44 \%)$ from patients with Wegener's granulomatosis. The sensitivity and specificity of a positive ANCA test result in this study were $65 \%$ and $77 \%$ respectively. For a diagnosis of Wegener's granulomatosis the sensitivity and positive predictive accuracy of a positive cytoplasmic ANCA (c-ANCA) test were greater than of a positive perinuclear ANCA (p-ANCA) test. There were 61 positive tests in 266 patients who did not have Wegener's granulomatosis (23\%); of these 27 were from patients with infection, 10 with fibrotic lung disease, nine with underlying connective tissue disease, seven with malignancy, and five following pulmonary emboli. Most of these positive ANCA results were pANCA (69\%) rather than c-ANCA (31\%). Serial ANCA requests were made in 15 cases of patients without Wegener's granulomatosis who had an initial positive ANCA test result. In all cases the ANCA tests subsequently became negative.

Conclusions - In this study the sensitivity and specificity of a positive ANCA test result were less than that reported from specialised centres. However, the test was found to be useful in clinical practice, especially c-ANCA, in conjunction with clinical symptoms of respiratory pathology and evidence of renal disease.

(Thorax 1994;49:213-217)

The first clinical report of Wegener's granulomatosis was made in $1931,{ }^{1}$ and later defined as a distinct clinical and pathological entity by Wegener in $1936 . .^{23}$ Classical or generalised Wegener's granulomatosis is characterised by necrotising granulomatous vasculitis of the upper and lower respiratory tract together with glomerulonephritis. ${ }^{4}$

More recently van der Woude and coworkers reported an association between the presence of antineutrophil cytoplasm autoantibodies (ANCA) and Wegener's granulomatosis. ${ }^{5}$ Several studies have confirmed this association and reported that a positive result has a sensitivity and specificity in excess of $90 \%$ for Wegener's granulomatosis. ${ }^{67}$ Most such series have been reported from specialist units, and the high sensitivity and specificity of the test may have been biased by the referral patterns. Other reports have recorded positive ANCA tests in patients with HIV infection, ${ }^{89}$ pulmonary tuberculosis, ${ }^{10}$ and lung cancer. ${ }^{11}$

Wegener's granulomatosis is a rare disease and therefore most UK respiratory physicians only see a small number of cases. ${ }^{12}$ The largest reported series are from specialist tertiary referral centres in the USA, ${ }^{1314}$ and it may be that their experience differs from that of UK physicians.

To determine the sensitivity and specificity of the ANCA test in everyday clinical practice we audited the results from all patients from the south west of England who had presented with respiratory symptoms and had an ANCA test requested in 1990. ANCA tests were performed on all requests made and in all cases the ANCA test was performed according to the recommendations set out in the broadsheet of the British Association of Clinical Pathologists. ${ }^{15}$

\section{Methods}

PATIENTS

In 1990 our reference laboratory received one or more requests for ANCA testing on 335 patients who had presented with respiratory 
symptoms, 194 of whom were men and 141 women of median age 63 (range 9-87) years.

The diagnosis of Wegener's granulomatosis was made using established criteria after Barlow and Fauci, ${ }^{16}$ as an illness with destructive upper or lower respiratory tract disease, or both, accompanied by glomerulonephritis in most cases. Diagnosis was confirmed when a biopsy showed small vessel vasculitis or venulitis, or both, or a necrotising/crescentic glomerulonephritis. If the inflammation was limited to a single site the additional histological documentation of granuloma was required to substantiate the diagnosis.

Wherever possible case notes and necropsy reports were reviewed, otherwise clinical data were obtained by questionnaire followed by consultation with the requesting doctor. Data were recorded on a standard form documenting symptoms and signs, previous medical history, laboratory investigations, histology, treatment, and outcome.

\section{STUDY DESIGN}

Preparation of neutrophils

Fresh human granulocytes were separated from heparinised whole blood by Polyprep (Nycomed, Birmingham, UK) sedimentation and diluted to a concentration of $0 \cdot 1 \times 10^{9} / 1$ in phosphate buffered saline (PBS)/bovine serum albumin. Neutrophil suspension, $300 \mu \mathrm{l}$, was added to the cuvette of the cytocentrifuge slide and spun on to the slides at $2000 \mathrm{rpm}$ for three minutes. The slides were air dried and fixed either directly in cold ethanol $\left(4^{\circ} \mathrm{C}\right)$ for 15 minutes or by immersion in formaldehyde/ acetone fixative ( $9 \%$ formaldehyde, $45 \%$ acetone and $46 \%$ PBS) for 50 seconds before immersion in cold ethanol for 15 minutes. All slides were air dried and stored with desiccant at $-20^{\circ} \mathrm{C}$.

\section{Indirect immunofluorescence assay}

Test or control sera diluted 1/10 in PBS were added to slides and incubated for 20 minutes at room temperature. The slides were washed twice with PBS and bound antibody was detected by fluorescence microscopy after incubation with fluorescein-isothiocyanate conjugated antihuman IgG (Fc piece) (Dakopatts, Copenhagen, Denmark).

\section{Definition of $c-A N C A$ and $p-A N C A$}

Sera were recorded as c-ANCA positive if cytoplasmic staining was in a granular pattern with central accentuation, and p-ANCA positive if staining was perinuclear on ethanol fixed slides and cytoplasmic on formaldehyde/acetone fixed slides. Positive sera were retested at serial twofold dilutions to a titre of $1 / 320$.

Positive nuclear and perinuclear sera were also tested for other autoantibodies by immunofluorescence against a composite block of rat liver, kidney, stomach, and oesophagus at a $1 / 10$ dilution. Positive antinuclear antibodies were titrated. Rheumatoid factor was detected by latex or the Rose Waaler test, or both.
Negative control sera were obtained from healthy AB blood donors and positive controls from patients with biopsy proven Wegener's granulomatosis.

\section{Quality control}

The regional reference laboratory belongs to the UK external quality assurance scheme for ANCA. Analysis of internal quality control samples showed that positive results did not vary by more than one dilution. In our laboratory between batch coefficients of variation for c-ANCA and p-ANCA were $4.5 \%$ and $6.6 \%$ respectively.

\section{STATISTICAL ANALYSIS}

The $\chi^{2}$ test with Yates' correction, if appropriate, was used to analyse the data. Statistical significance was taken at or below the $5 \%$ level.

Specificity is a measure of the incidence of negative results in subjects known to be free of the disease and sensitivity a measure of the incidence of positive results in subjects known to have the disease. However, a highly specific and sensitive test may still detect a significant number of "false positives," especially if the condition has a low prevalence. ${ }^{17}$ More useful is the concept of positive predictive value, which is the percentage of positive tests which are "true positives."17

\section{Results}

Clinical data were obtained from all 335 patients with respiratory tract symptoms for whom an ANCA test was requested in 1990. The majority of requests were made by respiratory physicians $(168(50 \%))$, followed by nephrologists $(79(24 \%))$, general physicians (63 (19\%)), otolaryngologists/ophthalmic surgeons $(19(6 \%))$, and pathologists (six $(2 \%))$. There were 106 positive ANCA results, 54 c-ANCA and 52 p-ANCA.

The case notes and necropsy reports were reviewed in 231 cases $(69 \%)$, including all those patients with a positive ANCA result. In the remaining cases information was obtained by the standard questionnaire and confirmed where necessary by the attending physician.

The median duration of follow up in the surviving patients with positive ANCA results was 31 months (range 25-38), and no patient with an initial positive ANCA result but with no supporting evidence of Wegener's granulomatosis has gone on to develop the disease.

\section{WEGENER'S GRANULOMATOSIS}

A final diagnosis of Wegener's granulomatosis was made in 69 cases, 45 men and 24 women of mean age 65 (range $20-83$ ) years; $35(51 \%)$ had a positive c-ANCA, of which 25 had a titre of $1 / 80$ or greater, and 10 had a positive p-ANCA $(14 \%)$, of which nine had a titre of $1 / 80$ or greater. Twenty four patients with Wegener's granulomatosis $(35 \%)$ had a negative ANCA test result. 
Table 1 Percentage sensitivity and specificity of a positive ANCA result in those patients with Wegener's granulomatosis (WG) at titres of $1 / 10$ and $1 / 80$ or greater

\begin{tabular}{|c|c|c|c|c|c|c|}
\hline & \multicolumn{2}{|c|}{ Sensitivity } & \multicolumn{2}{|c|}{ Specificity } & \multicolumn{2}{|c|}{$\begin{array}{l}\text { Positive predictive } \\
\text { accuracy }\end{array}$} \\
\hline & $1 / 10$ & $1 / 80$ & $1 / 10$ & $1 / 80$ & $1 / 10$ & $1 / 80$ \\
\hline $\begin{array}{l}\text { All positive ANCA } \\
\text { c-ANCA } \\
\text { p-ANCA }\end{array}$ & $\begin{array}{l}65 \\
51 \\
14\end{array}$ & $\begin{array}{l}49 \\
36 \\
13\end{array}$ & $\begin{array}{l}77 \\
78 \\
76\end{array}$ & $\begin{array}{l}84 \\
79 \\
77\end{array}$ & $\begin{array}{l}42 \\
65 \\
19\end{array}$ & $\begin{array}{l}45 \\
71 \\
22\end{array}$ \\
\hline
\end{tabular}

Sensitivity $=$ WG with positive ANCA test $\times 100$ Specificity $=\frac{\text { patients without WG with negative } A N C A \text { result }}{\text { all patients without WG }} \times 100$.

Positive predictive accuracy $=\frac{\text { WG with positive ANCA test }}{\text { all positive } A N C A \text { tests }} \times 100$.

At the time of ANCA testing $28(41 \%)$ had clinically active disease, of whom $18(64 \%)$ had a positive ANCA test result (15 c-ANCA and three p-ANCA). The remaining 41 cases with Wegener's granulomatosis were in remission, $27(60 \%)$ of whom had a positive ANCA result (20 c-ANCA and seven p-ANCA). The sensitivity and specificity of a positive ANCA result in patients with Wegener's granulomatosis is set out in table 1 .

\section{Positive ANCA Results in PATIENTS} WITHOUT WEGENER'S GRANULOMATOSIS

There were 61 positive ANCA results in the remaining 266 patients, 149 men and 117 women of mean age 62 (range 9-87) years. Forty two of these 61 patients had a positive pANCA result, with 32 having a titre of $1 / 80$ or greater, and $19(31 \%)$ had a positive c-ANCA result, 10 with a titre of $1 / 80$ or greater. The final diagnosis in these cases is set out in table 2.

Table 3 sets out symptoms and investigations at presentation in those patients without Wegener's granulomatosis who had positive ANCA results and those who did not.

Table 4 compares the symptoms and investigations in the patients with Wegener's granulomatosis with those 266 patients who had respiratory symptoms but did not have Wegener's granulomatosis.

Table 2 Patients with positive ANCA results without any evidence of Wegener's granulomatosis $(n=61)$ compared with those patients with a similar final diagnosis $(n=159)$ with a negative ANCA test result. Patients with other clinioal conditions who did not have a positive $A N C A$ result are excluded

\begin{tabular}{|c|c|c|c|c|c|c|}
\hline \multirow[t]{2}{*}{ Final diagnosis } & \multirow{2}{*}{$\begin{array}{l}\text { Positive } \\
A N C A\end{array}$} & \multirow{2}{*}{$\begin{array}{l}\text { Negative } \\
\text { ANCA }\end{array}$} & \multicolumn{2}{|c|}{$c-A N C A$} & \multicolumn{2}{|c|}{$p-A N C A$} \\
\hline & & & $1 / 10$ & $1 / 80$ & $1 / 10$ & $1 / 80$ \\
\hline $\begin{array}{l}\text { Pneumonia } \\
\text { Empyema } \\
\text { Tuberculosis } \\
\text { Bronchiectasis } \\
\text { Viral infection }\end{array}$ & $\begin{array}{r}16 \\
3 \\
1 \\
3 \\
4\end{array}$ & $\begin{array}{r}44 \\
6 \\
7 \\
9 \\
2\end{array}$ & $\begin{array}{l}3 \\
1 \\
0 \\
0 \\
2\end{array}$ & $\begin{array}{l}2 \\
1 \\
1 \\
0 \\
1\end{array}$ & $\begin{array}{l}2 \\
1 \\
0 \\
1 \\
0\end{array}$ & $\begin{array}{l}9 \\
0 \\
0 \\
2 \\
1\end{array}$ \\
\hline $\begin{array}{l}\text { CFA } \\
\text { Fibrotic lung disease }\end{array}$ & $\begin{array}{l}5 \\
5\end{array}$ & $\begin{array}{r}9 \\
12\end{array}$ & $\begin{array}{l}0 \\
0\end{array}$ & $\begin{array}{l}0 \\
3\end{array}$ & $\begin{array}{l}1 \\
0\end{array}$ & $\begin{array}{l}4 \\
2\end{array}$ \\
\hline $\begin{array}{l}\text { Pulmonary embolus } \\
\text { Pericarditis }\end{array}$ & $\begin{array}{l}5 \\
2\end{array}$ & $\begin{array}{r}12 \\
4\end{array}$ & $\begin{array}{l}1 \\
1\end{array}$ & $\begin{array}{l}1 \\
0\end{array}$ & $\begin{array}{l}1 \\
0\end{array}$ & $\begin{array}{l}2 \\
1\end{array}$ \\
\hline $\begin{array}{l}\text { Rheumatoid lung } \\
\text { SLE lung } \\
\text { MPA }\end{array}$ & $\begin{array}{l}4 \\
1 \\
4\end{array}$ & $\begin{array}{r}10 \\
3 \\
2\end{array}$ & $\begin{array}{l}0 \\
0 \\
1\end{array}$ & $\begin{array}{l}0 \\
0 \\
0\end{array}$ & $\begin{array}{l}0 \\
1 \\
0\end{array}$ & $\begin{array}{l}4 \\
0 \\
3\end{array}$ \\
\hline $\begin{array}{l}\text { Primary lung cancer } \\
\text { Pulmonary metastases } \\
\text { Lymphoma }\end{array}$ & $\begin{array}{l}5 \\
1 \\
2\end{array}$ & $\begin{array}{r}26 \\
6 \\
5\end{array}$ & $\begin{array}{l}0 \\
0 \\
0\end{array}$ & $\begin{array}{l}0 \\
0 \\
1\end{array}$ & $\begin{array}{l}3 \\
0 \\
0\end{array}$ & $\begin{array}{l}2 \\
1 \\
1\end{array}$ \\
\hline
\end{tabular}

$\mathrm{CFA}=$ cryptogenic fibrosing alveolitis; $\mathrm{SLE}=$ systemic lupus erythematosis; $\mathrm{MPA}=$ microscopic polyarteritis.

\section{Discussion}

Wegener's granulomatosis is a disease which commonly affects the upper and lower respiratory tracts and kidneys. ${ }^{416}$ Most requests for ANCA tests in this study came from renal and respiratory physicians. Surprisingly few requests were made by otolaryngologists.

The sensitivity and specificity of the ANCA test for patients with Wegener's granulomatosis was less than that reported in earlier studies. ${ }^{57}$ Most are from specialist centres and are likely to be subject to selection bias. By including all referrals for an ANCA test from the south west of England, a population of some 3.4 million, we had hoped to avoid any selection bias that may have been present in previous series from highly specialised centres.

Other workers have suggested that the sensitivity and specificity of the test can be increased only by including those patients with clinically active disease. ${ }^{6}$ In this series there was no difference in terms of the number of patients with positive ANCA results or the ANCA titre between those with active disease and those in remission. It has been suggested that the specificity of the test can be improved by restricting analysis to patients in whom there is high clinic 1 suspicion of Wegener's granulomatosis. ${ }^{18}$ In our series restricting analysis to patients presenting with respiratory tract symptoms did not result in the sensitivity or specificity of previously published series. ${ }^{19} 20$ From involvement in external quality assurance schemes we have no reason to believe that our assay performed less efficiently than that used in other laboratories.

In our series the sensitivity and positive predictive value for a c-ANCA result in a patient presenting with respiratory symptoms was much greater than that of a p-ANCA result. This supports some of the earlier studies. $^{57}$

Sixty one patients presenting with respiratory symptoms had a positive ANCA test result compared with 45 patients with proven Wegener's granulomatosis. The eventual diagnosis in these patients fell into five major groups: pulmonary infection, most commonly bacterial and lower respiratory tract; fibrosing lung disease; connective tissue diseases associated with vasculitis; tumours; and pulmonary embolic disease. The clinical presentation and routine haematological, biochemical, immunological, and radiological investigations were similar in those patients without Wegener's granulomatosis who had both positive and negative ANCA results.

More of those patients with a positive ANCA result had increased serum IgG concentrations. One possible explanation for a positive ANCA result is non-specific IgG binding, and this has been suggested in previous studies which have reported positive results in patients with underlying infections. ${ }^{910}$ Some tumours such as lymphomas are known to affect the immune system and may affect immunoglobulin synthesis. However, we have not been able to show any relation between serum IgG concentration and ANCA titre. Positive results may be expected in 
Table 3 Symptoms and test results (expressed as percentages) in those patients who did not have Wegener's granulomatosis but either had a positive $(n=61)$ or a negative $(n=205)$ ANCA test result

\begin{tabular}{llcr}
\hline & Negative ANCA & Positive ANCA & $1 / 80$ ANCA \\
\hline Respiratory symptoms & 92 & 94 & 84 \\
Sinus symptoms & 11 & 6 & 0 \\
Abnormal chest radiograph & 81 & 88 & 100 \\
Abnormal sinus radiograph & 8 & 0 & 0 \\
Anaemia (Hb $<10$ g/d1) & 16 & 28 & 11 \\
Neutrophilia & 24 & 30 & 44 \\
Thrombocythaemia & 22 & 17 & 63 \\
Increased CRP/plasma viscosity & 65 & 73 & 22 \\
Positive ANF & 34 & 14 & 27 \\
Positive DNA binding & 11 & 8 & 38 \\
Positive rheumatoid factor & 17 & $57^{*}$ & 22 \\
Increased IgG & 18 & 24 & 11 \\
Urine dipstick protein & 20 & 12 & 96 \\
Urine dipstick blood & 16 & 96 & 2 \\
Serum creatinine $\leqslant 150 \mu \mathrm{mol} / 1$ & 88 & 2 & 2 \\
Serum creatinine $>150$ to $\leqslant 500 \mu \mathrm{mol} / 1$ & 10 & 2 & \\
Serum creatinine $>500 \mu \mathrm{mol} / 1$ & 2 & &
\end{tabular}

$\mathrm{CRP}=\mathrm{C}$ reactive protein; $\mathrm{ANF}=$ antinuclear factor; $\mathrm{IgG}=$ immunoglobulin $\mathrm{G}$.

${ }^{*} \mathrm{p}<0.05 v$ true negatives $\left(\chi^{2}\right.$ test).

patients with vasculitis and connective tissue diseases. Both p-ANCA and c-ANCA staining have been reported in association with microscopic polyarteritis, ${ }^{18}$ and antineutrophil nuclear antibodies were first described in patients with rheumatoid arthritis. ${ }^{21}$ Others have reported atypical ANCA staining in patients with connective tissue diseases. ${ }^{22}$ The role of ANCA has yet to be clarified. In vitro experiments suggest that it prevents activated neutrophils from downregulation and thus may allow further endothelial damage. ${ }^{23}$ However, the same mechanism may be important in tissue repair designed to remove excess fibrin and other products of tissue inflammation. Those patients with fibrotic pulmonary disease, pulmonary malignancy, respiratory infection, or embolic disease may have suffered some pulmonary vascular damage and thereby developed ANCA as a natural consequence of endothelial damage and repair.

In this study we restricted the audit to the first ANCA test request made in 1990 . Of the 61 patients who had an initial positive test result, $15(26 \%)$ had further requests. All ANCA results subsequently became negative, although in some cases this took up to three months. This differs from the results of serial ANCA tests in those patients who presented

Table 4 Presenting symptoms and initial investigations in those patients with Wegener's granulomatosis $(n=69)$ who had positive $(n=45)$ and negative $(n=14)$ ANCA results and those patients without Wegener's granulomatosis $(n=266)$. Results are expressed as percentages

\begin{tabular}{|c|c|c|c|c|}
\hline & $\begin{array}{l}\text { All } \\
\text { Wegener's }\end{array}$ & $\begin{array}{l}\text { Wegener's } \\
\text { positive ANCA }\end{array}$ & $\begin{array}{l}\text { Wegener's } \\
\text { negative } A N C A\end{array}$ & $\begin{array}{l}\text { Other } \\
\text { conditions }\end{array}$ \\
\hline $\begin{array}{l}\text { Respiratory symptoms } \\
\text { Sinus/nasal symptoms } \\
\text { Aural symptoms } \\
\text { Abnormal chest radiograph } \\
\text { Abnormal cavitation } \\
\text { Abnormal sinus radiograph } \\
\text { Anaemia }(\mathrm{Hb}<10 \mathrm{~g} / \mathrm{dl}) \\
\text { Neutrophilia } \\
\text { Thrombocythaemia } \\
\text { Increased alkaline phosphatase } \\
\text { Increased CRP/PV } \\
\text { Positive ANF } \\
\text { Positive DNA binding } \\
\text { Positive rheumatoid factor } \\
\text { Increased IgG } \\
\text { Urine dipstick protein } \\
\text { Urine dipstick blood } \\
\text { Creatinine } \leqslant 150 \mu \mathrm{mol} / 1 \\
\text { Creatinine }>150 \text { to } \leqslant 500 \mu \mathrm{mol} / 1 \\
\text { Creatinine }>500 \mu \mathrm{mol} / 1\end{array}$ & $\begin{array}{r}87 \\
51 \\
26 \\
80 \\
25 \\
33 \\
38 \\
29 \\
17 \\
26 \\
59 \\
17 \\
4 \\
19 \\
22 \\
57 \\
53 \\
59 \\
23 \\
18\end{array}$ & $\begin{array}{l}96 \\
42 \\
31 \\
82 \\
28 \\
31 \\
40 \\
31 \\
18 \\
27 \\
67 \\
16 \\
2 \\
15 \\
33 \\
56 \\
53 \\
62 \\
22 \\
16\end{array}$ & $\begin{array}{l}71 \\
67 \\
17 \\
75 \\
17 \\
38 \\
33 \\
25 \\
17 \\
25 \\
54 \\
21 \\
8 \\
33 \\
20 \\
58 \\
54 \\
54 \\
25 \\
21\end{array}$ & $\begin{array}{l}87 \\
10^{*} \\
1^{*} \\
81 \\
8^{*} \\
6^{*} \\
23^{*} \\
27 \\
20 \\
29 \\
68 \\
31^{*} \\
9 \\
14 \\
24 \\
22^{*} \\
16^{*} \\
88^{*} \\
10 \\
2\end{array}$ \\
\hline
\end{tabular}

$\mathrm{CRP}=\mathrm{C}$ reactive protein; $\mathrm{PV}=$ plasma viscosity; $\mathrm{IgG}=$ immunoglobulin $\mathrm{G}$.
${ }^{p} \mathrm{p}<0.05 v$ all patients with $\mathrm{W}$ egener's granulomatosis. with active Wegener's granulomatosis where, despite aggressive immunosuppression, most still had positive ANCA titres after three months, albeit at reduced levels.

Those patients who were subsequently diagnosed as having Wegener's granulomatosis differed from those presenting with respiratory tract symptoms by having a greater frequency of nasal, sinus, and aural disease. More patients with Wegener's granulomatosis were anaemic and had greater renal involvement having both positive urine dipstick results and impaired renal function - as expected by the definition of Wegener's granulomatosis. ${ }^{16}$ More patients with Wegener's granulomatosis had the c-ANCA staining pattern $(78 \%)$ than p-ANCA $(22 \%)$. This is in contrast with the situation in those patients without Wegener's granulomatosis where only $31 \%$ of the positive ANCA results had the c-ANCA staining pattern and $69 \%$ p-ANCA. The c-ANCA pattern predominantly reflects the presence of antibody to proteinase III, ${ }^{20}$ whereas p-ANCA is more heterogeneous, reacting with several antigens of which myeloperoxidase is the most common. ${ }^{20}$

The indirect immunofluorescence test is the most widely available ANCA test in the UK. It may be that it should be used as a screening test and that positive samples should be further analysed by ELISA for proteinase III and myeloperoxidase. However, recent studies have shown that the indirect immunofluorescence test was more sensitive than the currently available ELISA assays in detecting patients with Wegener's granulomatosis, and that there was no difference in "false positive" results between the methodologies. ${ }^{24}$ This is supported by a recent international cooperative study group who suggested that indirect immunofluorescence ANCA tests remain the gold standard for patients with Wegener's granulomatosis who have antibodies for proteinase III. ${ }^{25}$

In this series of patients presenting with respiratory symptoms there were many positive ANCA results using the currently recommended indirect immunofluorescence test in patients who were ultimately found not to have Wegener's granulomatosis. This suggests that the usefulness of a positive indirect immunofluorescence ANCA test is not as great as has been reported, and that a diagnosis of Wegener's granulomatosis should not be made solely on the basis of an ANCA result without other corroborative proof.

In most cases with initial "false positive" ANCA results serial determinations became negative with time, so repetition of the test may be more helpful than a single result. However, the ANCA test was found to be useful in helping to support the diagnosis of Wegener's granulomatosis, especially when of the c-ANCA pattern and in association with the combination of upper and lower respiratory tract symptomatology in a patient with abnormal urine stick testing and raised blood creatinine concentrations.

We wish to thank all our colleagues in the South Western Region for their help and cooperation in this study. 
1 Klinger H. Grenzformen der periarteritis nodosa. Frankfurt $Z$ Pathol 1931;42:455-80.

2 Wegener $F$. Uber generalisierte septische Gefasserkrankungen. Verh Dtsch Ges Pathol 1936;29:202-10.

3 Wegener F. Uber eine eigenartige rhinogene Granulomatose mit besonderer Beterligung des Arteriensystems und der Nieren. Beitr Pathol 1939;102:36-68.

4 Fauci AS, Wolff SM. Wegener's granulomatosis: studies in eighteen patients and a review of the literature. Medicine eighteen patients

5 van der Woude FJ, Rasmussen N, Lobatto S, Wiik A, Permin $\mathrm{H}$, van Es LA, et al. Autoantibodies against neutrophils and monocytes: tool for diagnosis and marker for disease activity in Wegener's granulomatosis. Lancet 1985;i:425-9.

6 Cohen Tervaert JW, van der Woude FJ, Fauci AS, Ambrus $\mathrm{JL}$, Velosa J, Keane WF, et al. Association between active Wegener's granulomatosis and anticytoplasmic antibodies. Arch Intern Med 1989;149:2461-5.

7 Nolle B, Specks U, Ludemann MS, Rohrbach MS, DeRemee RA, Gross WL. Anticytoplasmic autoantibodies: their immunodiagnostic value in Wegener's granulomatotheir immunodiagnostic value in We

8 Koderisch J, Andrassy K, Rasmussen N, Hartmann M, Tiglen W. "False positive" antineutrophil cytoplasmic antibodies in HIV infection. Lancet 1990;i:716-7.

9 Davenport A, Grant PJ. False positive autoantibodies in HIV infection. Lancet 1990;ii:317-8.

10 Davenport A. "False positive" perinuclear and cytoplasmic antineutrophil cytoplasmic antibody results leading to misdiagnosis of Wegener's granulomatosis and/or microscopic polyarteritis. Clin Nephrol 1992;37:124-30.

11 Harrison DJ, Simpson R, Kharbanda R, Abernathy VE, Nimmo G. Antibodies to neutrophil cytoplasmic antigens in Wegener's granulomatosis and other conditions. Thorax 1989;44:373-7.

12 Anderson G, Coles ET, Crane M, Douglas AC, Gibbs AR, Geddes DM, et al. Wegener's granuloma. A series of 265 British cases seen between 1975 and 1985. A report by a British cases seen between 1975 and 1985 . A report by a
sub-committee of the British Thoracic Society Research Committee. $Q$ f Med 1992;302:427-38.
13 McDonald TJ, DeRemee RA. Wegener's granulomatosis Laryngoscope 1983;93:220-31.

14 Fauci AS, Haynes BF, Katz P, Wolff SM. Wegener's granulomatosis: prospective clinical and therapeutic experience with 85 patients for 21 years. Ann Intern Med 1983;98:76-85.

15 Lock RJ. Detection of autoantibodies to neutrophil cytoplasmic antigens. $\mathcal{f}$ Clin Pathol 1994;47:4-8.

16 Barlow JE, Fauci AS. Vasculitic diseases of the kidney: polyarteritis nodosa. Wegener's granulomatosis, allergic angiitis and granulomatous and other disorders. In: Schroder RW, Gottschalk CW, eds. Diseases of the kidney. 4th edition. New York: Little Brown, 1988:2335-60.

17 Marshall WJ. Biochemical tests in clinical medicine. In: Marshall WJ. The illustrated textbook of clinical chemistry. London: Gower, 1988:6-8.

18 Falk RJ. ANCA associated renal disease. Kidney Int 1990;38:999-1010.

19 Higgs CMB, Sampson MB. Clinical usefulness of the antineutrophil cytoplasmic antibody test. Thorax 1990;45:305.

20 Harrison DJ, Simpson R, Kharbanda R, Abernethy VE, Nimmo G. Antibodies to neutrophil cytoplasmic antigens Nimmo G. Antibodies to neutrophil cytoplasmic antigens in Wegener's granul

21 Faber V, Elling P, Norup G, Mansa B, Nissen NI. An antinuclear factor specific for leukocytes. Lancet 1964;ii:344-5.

22 Lesavre P. Antineutrophil cytoplasmic autoantibodies antigen specificity. Am f Kidney Dis 1991;18:159-63.

23 Ewert BH, Jennette JC, Falk RJ. The pathogenic role of antineutrophil cytoplasmic autoantibodies. $A m \mathcal{F}$ Kidney Dis 1991;18:188-95.

24 Weidemann S, Andrassy K, Ritz E. ANCA in haemodialysis patients. Nephrol Dial Transplant 1993;9:839-45.

25 Hagen EC, Andrassy K, Chernok E, Daha MR, Gaskin G, Gross W, et al. The value of indirect immunofluorescence and solid phase techniques for ANCA detection. A report and solid phase techniques for ANCA detection. A report on the first phase of an international co-operative study on
the standardisation of ANCA assays. $\mathcal{F}$ Immunol Methods 1993;159:1-16. 